\title{
Minimum energy strategies for the in-plane behaviour of masonry
}

\author{
Antonio Gesualdo*, Bruno Calderoni \\ University of Naples 'Federico II", Department of Structure for Engineering and Architecture, Napoli, Italy \\ Via Claudio 21, 80125, Napoli, Italy \\ gesualdo@unina.it, bttp:// orcid.org/0000-0002-7063-8064 \\ calderon@unina.it, bttps:/ / orcid.org/0000-0001-5596-9829
}

\author{
Antonino Iannuzzo \\ ETH Zürich, Institute of Technology in Architecture, Zürich, Switzerland \\ iannuzzo@arch.ethz.ch, bttp://orcid.org/0000-0002-6633-149X
}

\section{Antonio Fortunato}

University of Salerno, Department of Civil Engineering, Fisciano (SA), Italy

a.fortunato@unisa.it, bttps://orcid.org/0000-0001-9224-2143

\section{Michela Monaco \\ University of Campania 'Luigi V anvitelli", Department of Architecture and Industrial Design, Aversa (CE), Italy michela.monaco@unicampania.it, bttp:/ / orcid.org/0000-0001-7895-7089}

\begin{abstract}
Unreinforced masonry is the most diffused construction material in the major part of historical centers in Europe. In a building subjected to earthquake forces the contribution of in-plane shear resistance of the masonry walls is a determinant factor for the stability of the whole structure. In particular, the masonry piers are the structural elements subjected to the combination of normal and shear forces. In general, ductile tools to model the in plane behaviour of masonry are always welcome in order to evaluate the capacity of walls subjected to vertical and horizontal actions. In this framework, two no-tension approaches to model the behaviour of masonry walls loaded with in-plane forces, involving a minimum energy procedure, are presented. Both the procedures allow the representation of the stress maps in the panel in case of monotonic increase of shear load. The results of the numerical analyses are compared and discussed.
\end{abstract}

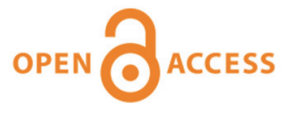

Citation: Gesualdo, A., Calderoni, B., Iannuzzo, A., Fortunato, A., Monaco, M. Minimum energy strategies for the in-plane behaviour of masonry, Frattura ed Integrità Strutturale, 51 (2020) 376-385.

Received: 28.09 .2019

Accepted: 25.11 .2019 Published: 01.01.2020

Copyright: (C) 2020 This is an open access article under the terms of the CC-BY 4.0, which permits unrestricted use, distribution, and reproduction in any medium, provided the original author and source are credited.

KEYWORDS. Masonry; In-plane loads; Minimum potential energy.

\section{INTRODUCTION}

$\mathrm{T}$ he analysis of masonry structures has been for years a challenging issue to be addressed, especially when seismic actions are involved. Masonry buildings are in fact the main part of historical centers in Italy and in general all over Europe [1]. These buildings are a complex arrangement of masonry walls and different structural elements, 
such as arches and vaults, columns and plane slabs [2]. Henceforth existing masonry buildings subjected to seismic loads need a correct modeling of these structural elements and their interaction [3]. In particular, especially in the cases in which the out of plane mechanisms can be considered absent [4], the role of the in plane behavior of masonry elements (piers and spandrels) and their interaction with the horizontal structural elements is a key one [5, 6]. Given the importance of the masonry heritage and in view of its rehabilitation, efficient and consistent tools are needed [7], especially constitutive models able to describe the complex patterns of cracks after static and dynamic actions $[8,9,10]$. Several constitutive models have been proposed in the last decades to describe the behaviour of masonry, and among them a preminent role can be assigned to the No-Tension (NT) model. The first approaches to the unilateral model date back to nineteenth century, [11], although in the indeterminate case of the rectangular table with four legs the problem was for the first time posed in an indirect way by Euler at the end of XVIII century [12]. The first rational consideration on the constitutive model were developed in the first decades of XIX century by Signorini [13]. The papers by Heyman [14, 15] considered the low tensile stress of masonry negligible, so that a NT material could be taken into account. He introduced the safe theorem of limit analysis for particular masonry structures, according to which an unreinforced masonry vault will stand if a network of compression forces in the section of the structure and in equilibrium with the applied loads can be found. This solution can be considered according the statements of limit analysis a lower-bound solution [16, 17] and was presented for the first time as an application to the case of "voussoir" (or segmental) arch [18], as the author pointed out. Since that time, and with limited exceptions [19-21] the NT problem has become an almost exclusively Italian question. The first rational assessment was developed since the beginnings of ' 80 and mainly thanks to Italian contribute, see for example [22, 23].

The classical Heyman hypotheses of null tensile strength, infinite compressive strength and no-sliding were since then the basis his theory, together with the static theorem of limit analysis, used mainly for the analysis of arches and vaults [24]. The Heyman hypotheses and the limits of their application to masonry structures were successively discussed [25].

This paper presents two NT approaches to model the behaviour of masonry walls subjected to in-plane actions. In both cases a variational strategy is proposed. An extremum problem is in fact solved, in the first case with reference to the complementary energy, in the second one to the potential energy. The first method considers an approximate solution when small strains are involved, with the constitutive hypothesis of unilateral constraints on normal stresses. The solution is a kinematically consistent configuration obtained as a minimum for the complementary energy $E_{c}$. The numerical problem is solved introducing a curvilinear coordinate system corresponding to the distribution of compression rays [26]. The second approach solves the problem of a 1-D element with variable cross section and symmetric shape defined in the panel domain and corresponding to the compressed area. The solution corresponds to the minimum of total potential energy [27]. The stress maps in case of monotonic increase of shear load is provided [28].

\section{ELASTIC NO-TENSION MODEL}

\section{General definitions}

7 he mechanics of masonry-like -materials, developed by Giaquinta and Giusti [22] and Del Piero [23]. Fortunato [26] considered the boundary value problem for a masonry-like rectangular panel, traction free on the lateral sides and subjected to zero body forces as well as prescribed rigid body displacements of the top and bottom bases. In particular, the problem is that of a NT body occupying a two dimensional regular region $\Omega$ (Fig. 1), with:

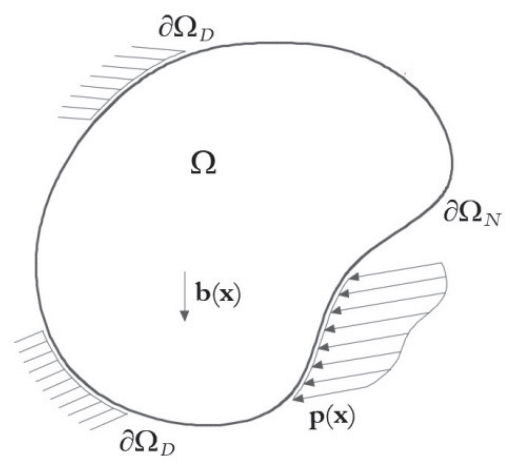

Figure 1: The NT body. 


$$
\begin{array}{ll}
\partial \Omega=\partial \Omega_{N} \cup \partial \Omega_{D}: & \text { boundary of the body } \Omega \text { and } \partial \Omega_{N} \cap \partial \Omega_{D}=\varnothing \\
\partial \Omega_{N}, \partial \Omega_{D}: & \text { free and constrained boundary of the body } \Omega .
\end{array}
$$

Given the body forces $\mathbf{b}$ in $\Omega$, the tractions $\mathbf{p}$ on $\partial \Omega_{N}$ and the displacements $\overline{\mathbf{u}}$ on $\partial \Omega_{D}$, the solution of the boundary value problem is the triplet $\{\mathbf{u}, \boldsymbol{\lambda}, \mathbf{b}\}$ (displacement, anelastic strain, stress) fulfilling the following relations:

- equilibrium and static boundary conditions

$$
\operatorname{div} \mathbf{T}+\mathbf{b}=\mathbf{0} \quad, \quad \mathbf{T n}=\mathbf{p} \quad, \quad \text { on } \partial \mathbf{\Omega}_{N}
$$

- kinematic boundary conditions

$$
\mathbf{u}=\overline{\mathbf{u}}, \quad \text { on } \partial \Omega_{D}
$$

- stress-strain law and constitutive restrictions on strain involving fractures

$$
\mathbf{T}=\mathbb{C}[\mathbf{e}-\lambda], \quad \operatorname{tr} \mathbf{T} \leq 0, \quad \operatorname{det} \mathbf{T} \geq 0
$$

- normality law

$$
\operatorname{tr} \lambda \geq 0, \operatorname{det} \lambda \geq 0, \quad \mathbf{T} \cdot \lambda=0
$$

where $\mathbf{e}$ is the infinitesimal strain and $\mathbb{C}$ is the elastic tensor. The inequalities (3) lead to the following partition of the domain $\Omega$ :

$$
\begin{aligned}
& \Omega_{1}=\{\mathbf{x} \in \Omega: \operatorname{tr} \mathbf{T}<0, \operatorname{det} \mathbf{T}>0\} \\
& \Omega_{2}=\{\mathbf{x} \in \Omega: \operatorname{tr} \mathbf{T}<0, \operatorname{det} \mathbf{T}=0\} \\
& \Omega_{3}=\{\mathbf{x} \in \Omega: \operatorname{tr} \mathbf{T}=0, \operatorname{det} \mathbf{T}=0\} .
\end{aligned}
$$

The domain $\Omega_{1}$ is that of biaxial compression and the material has the classical bilateral elastic behaviour. In the domain $\Omega_{2}$ the material is in uniaxial compression and can show fractures. In this case the compressive lines when $\mathbf{b}=\mathbf{0}$ are straight lines. In the $\Omega_{3}$ domain the material is completely inert and any positive semidefinite fracture field is possible.

\section{Variational formulation}

It has been proved [23] the existence of a strain energy density for NT materials, so that a variational formulation of the problem can be derived, i.e. an equilibrium configuration corresponds to a minimum of the total Potential Energy:

$$
E_{p}(\mathbf{u})=\frac{1}{2} \int_{\Omega} \mathbf{E} \cdot \mathbb{C} \mathbf{E}-\int_{\partial \Omega_{N}} \mathbf{p} \cdot \mathbf{u} d s .
$$

The equilibrium displacement solution may not be unique, due to the presence of the anelastic part. A dual formulation of the problem has been derived by [22], with the stress field $\mathbf{T}^{0}$ as statically admissible solution minimizing the Complementary Energy functional:

$$
E_{c}(\mathbf{T})=\frac{1}{2} \int_{\Omega} \mathbf{T} \cdot \mathbb{C}^{-1} \mathbf{T}-\int_{\partial \Omega_{D}} \mathbf{T n} \cdot \overline{\mathbf{u}} d s
$$

defined over the convex set of statically admissible stress fields. 


\section{ANALYTICAL FORMULATIONS OF THE VARIATIONAL PROBLEM}

\section{2-D Minimum complementary energy approach}

he analysis considers a NT masonry panel loaded with a constant vertical force and an increasing horizontal one. In the present approach the equilibrium solution is determined by minimizing the complementary energy (7) according the general method reported in [26]. The rectangular domain defined by the panel is traction free on the lateral sides. The body forces are null and the displacements are prescribed at top and bottom bases: the relative displacements of the two bases are defined by the triplet $\{U, V, \Phi\}$. A reference system $\{O, x, y\}$ is defined with origin in the panel centroid, see Fig. 2(a).
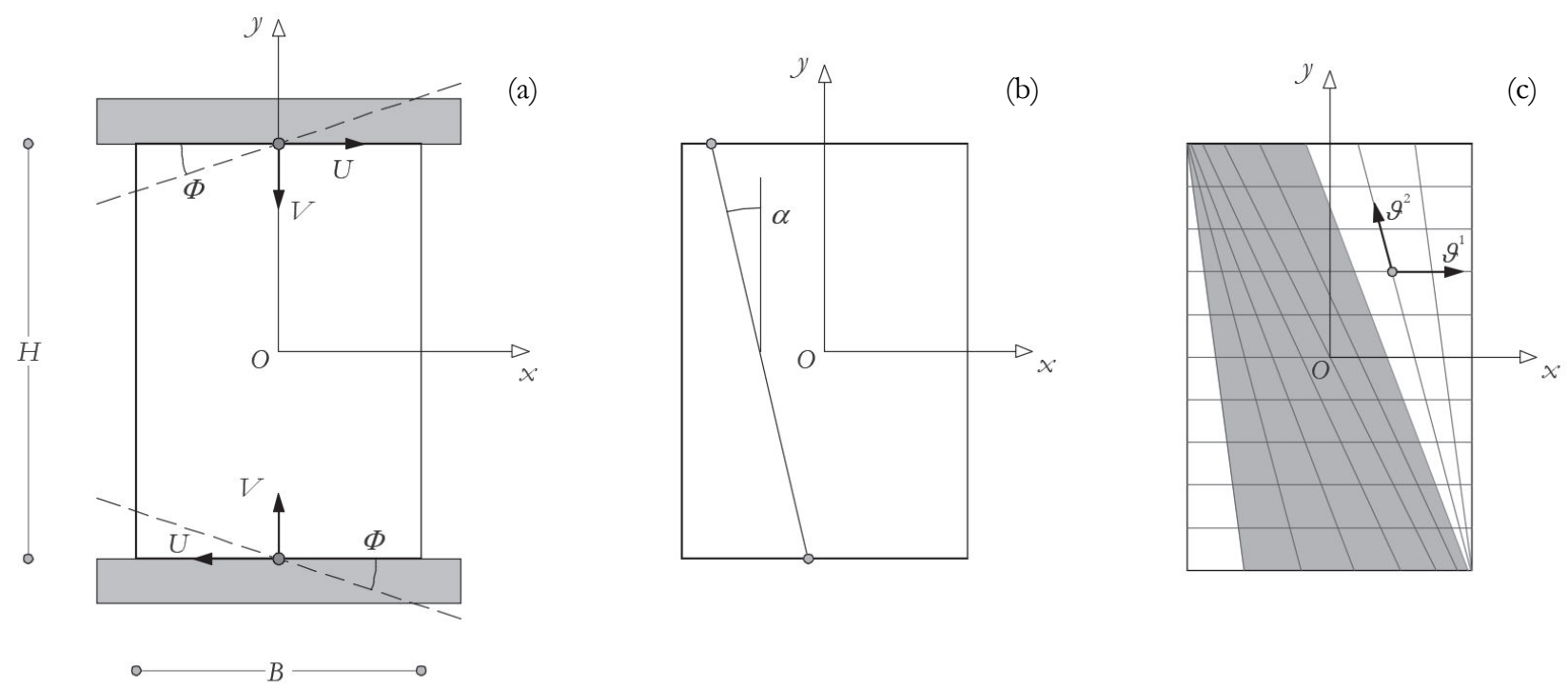

Figure 2: Masonry panel and displacement vectors (a); angle $\alpha$ with the vector rays (b); vector rays and coordinates system (c)

The problem is solved considering an approximate solution over a reduced definition domain, i.e. $\Omega_{2} \cup \Omega_{3}$, that is to search the statically admissible stress field $\mathbf{T}^{0}$ in $\Omega_{2}$ when the free boundary between $\Omega_{2}$ and $\Omega_{3}$ is determined. As above remarked, when the body forces are null, the isostatic compressive curves are straight lines, named compression rays. They form an angle $\alpha$ with the $y$ axis and cross the two bases of the panel, since the vertical edges are part of the free boundary. The curvilinear reference system for the compression rays is defined by the coordinate system $\left\{O, \vartheta^{1}, \vartheta^{2}\right\}$, see Fig. 2(c). Within the panel area an uniaxial thrust region is recognized. This compression region is determined by means of the complementary energy minimum. Reference is made to a normalized rectangle of unitary base and height $\bar{H}=B / H$ where $B$ and $H$ are respectively the real base and height of the masonry panel as in Fig. 2(a). The compression rays are defined by means of the slope function $g\left(\vartheta^{1}\right)$, subjected to the geometrical constraints:

$$
\begin{aligned}
-\frac{1-2 \vartheta^{1}}{\bar{H}} & \leq g\left(\vartheta^{1}\right) \leq \frac{1-2 \vartheta^{1}}{\bar{H}} \\
-\frac{1+2 \vartheta^{1}}{\bar{H}} & \leq g\left(\vartheta^{1}\right) \leq \frac{1+2 \vartheta^{1}}{\bar{H}}
\end{aligned}
$$

where $\vartheta^{1}$ is the intersection of the slope function with the horizontal axis. The constitutive conditions: 


$$
g\left(\vartheta^{1}\right)>-\frac{V}{U}-\frac{\Phi}{U} \vartheta^{1} \quad, \quad U>0
$$

correspond to the existence of compression rays corresponds to a kinematic constraint on the function $g\left(\vartheta^{1}\right)$. The Complementary Energy (7) assumes in this case the form (see Fortunato, 2010):

$$
E_{c}=-2 E \int_{\underline{g}^{1}}^{\bar{\vartheta}^{1}} \frac{\left(U g+V+\Phi \vartheta^{1}\right)^{2} g^{\prime 2}}{\left(1+g^{2}\right) \ln \left(\frac{1+g^{\prime} H / 2}{1-g^{\prime} H / 2}\right)} d \vartheta^{1}
$$

where the triplet $(U, V, \Phi)$ represents the given set of relative rigid displacements, $\bar{\vartheta}^{1}$ and $\underline{\vartheta}^{1}$ are the geometrical bounds of the compression region and $g^{\prime}$ is the first derivative of $g\left(\vartheta^{1}\right)$ with respect to $\vartheta^{1}$. The minimum of $E_{c}$ is obtained solving the Euler equation associated to (10) adopting a multiple shooting technique, in other words looking for the function $g\left(\vartheta^{1}\right)$ that minimizes the functional (10) with the constraints (9) and the boundary conditions:

$$
g\left(\underline{\vartheta}^{1}\right)=\underline{g} \quad, \quad g\left(\bar{\vartheta}^{1}\right)=\bar{g} .
$$

The conditions (11) correspond to the upper and lower load conditions.

\section{1-D Minimum potential energy approach}

Like in the previous paragraph, body forces are null and the analysis is performed considering a NT masonry panel loaded with a constant vertical force and an increasing horizontal one. As the horizontal load increases, the resultant force $R$ is that corresponding to the triangular distribution with base $A$ in Fig. 3(a). The straight line connecting the middle points of the triangular distribution forms and angle $\varphi_{1}$ with the vertical axis. A partition of the entire rectangular domain due to the constitutive model adopted is recognized, so that the compressive stress area $\Omega_{2}$ in (5) can be assumed that enclosed in the polygonal domain represented in Fig. 3(b), whose geometry is defined by:

$$
B_{\min }=A \cos \varphi_{2} \quad, \quad B_{\max }=\frac{B}{\cos \varphi_{2}}
$$

where $\varphi_{2}$ is the angle that the symmetry axis of the domain forms with the vertical one and in general it is distinct from $\varphi_{1}$. The problem is skew-symmetric with respect to the vertical axis, and the entire problem can be reduced to onedimensional model, i.e. a masonry strut with variable cross section and symmetric shape. The resulting problem is an Euler-Bernoulli cantilever beam with variable cross section as in Fig. 4(a), loaded by $R$. The internal forces on the beam are:

$$
N_{1}=R \cos \left(\varphi-\varphi_{2}\right) \quad, \quad T_{1}=R \sin \left(\varphi-\varphi_{2}\right) \quad, \quad M_{1}=N_{1}\left(\frac{B}{2}-\frac{A}{3}-\frac{H}{2} \tan \varphi_{2}\right) .
$$

The variational formulation of the problem in terms of potential energy $E_{p}(\mathbf{u})$ in $(6)$ is used. The boundary conditions are defined at the beam ends of Fig. 4 (b) and in the cross section where there is a stiffness first derivative variation. The problem solution is in this case the triplet $\left(\mathbf{v}_{B}, \mathbf{v}_{C}, \varphi_{2}\right)$ satisfying the displacements boundary conditions and minimizing the $E_{p}(\mathbf{u})$ expressed by:

$$
\begin{aligned}
E_{p}(\mathbf{u}) & =E_{p}\left(\mathbf{v}_{B}, \mathbf{v}_{C}, \varphi_{2}\right)= \\
& =\frac{1}{2}\left[\int_{0}^{L_{1}} E I_{1}\left(z_{1}\right) \chi_{1}^{2} d \xi_{1}+\int_{0}^{L_{2}} E I_{2}\left(\xi_{2}\right) \chi_{2}^{2} d \xi_{2}\right]+\frac{1}{2}\left[\int_{0}^{L_{1}} E A_{1}\left(\xi_{1}\right) \varepsilon_{1}^{2} d z_{1}+\int_{0}^{L_{2}} E A_{2}\left(\xi_{2}\right) \varepsilon_{2}^{2} d z_{2}\right]-\mathbf{F} \cdot \mathbf{v}_{C}
\end{aligned}
$$


where the integrals are defined over the two domains in which stiffness is continuous with its first derivative $E I_{i}, E A_{i}$, $\chi_{i}, \varepsilon_{i}$ are respectively the stiffness and deformation characteristics of the beam and the external force vector is $\mathbf{F} \equiv\left(N_{1}, T_{1}, M_{1}\right)$.
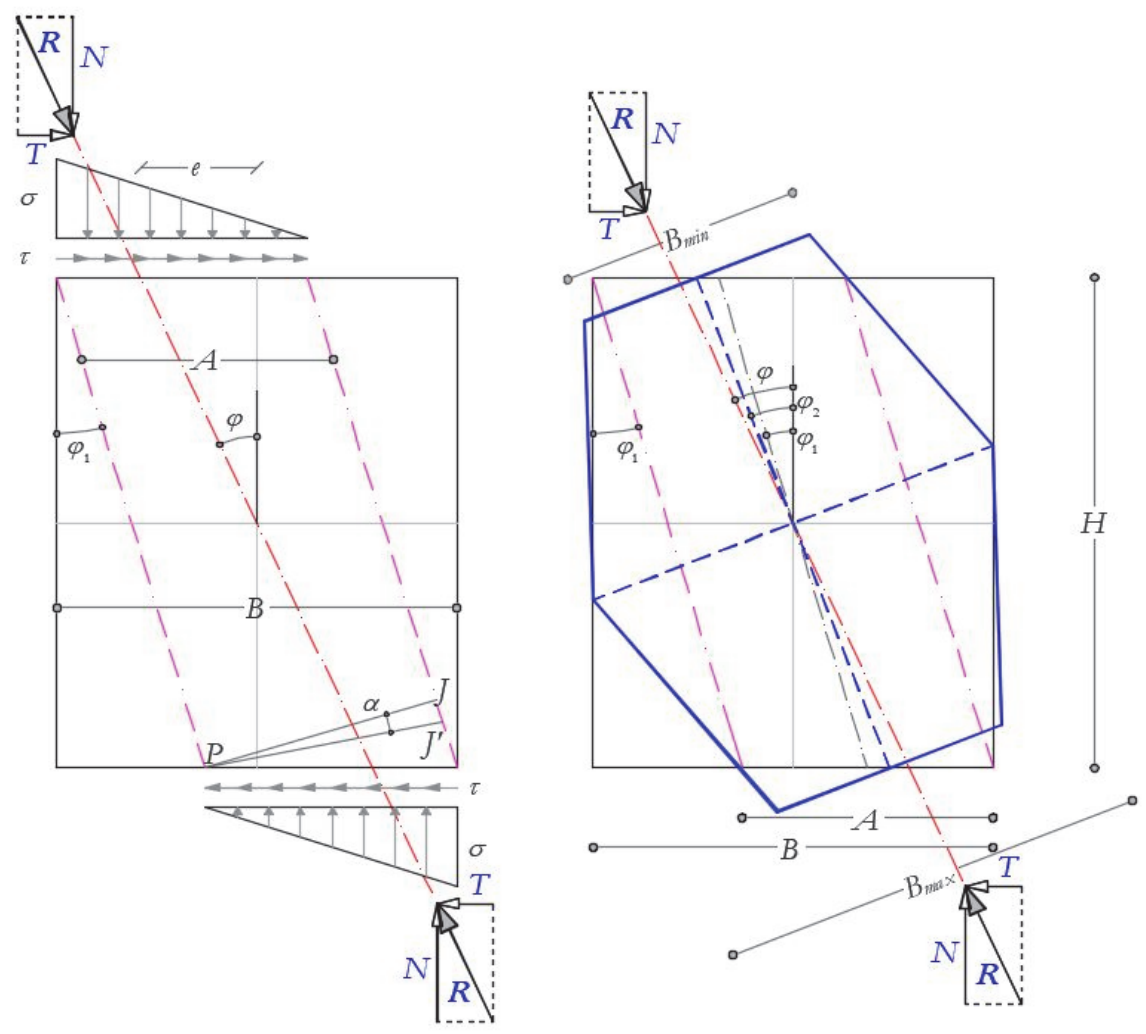

Figure 3: (a) Masonry panel with in-plane load; (b) Shape of the reacting structure.

Only the bending and the axial strain energies have been taken into account in the relation (13). The problem has been solved taking into account a fifth-order power series expansion for the angle $\varphi_{2}$ [29]. The minimum condition is given by:

$$
\nabla \phi\left(\mathbf{v}_{B}, \mathbf{v}_{C}, \varphi_{2}\right)=0
$$

and the boundary conditions:

$$
\begin{array}{ll}
v_{1}(0)=v_{B} ; & v_{2}(0)=v_{A}=0 \\
v_{1}^{\prime}(0)=\varphi_{B} ; & v_{2}^{\prime}(0)=\varphi_{A}=\alpha \\
v_{1}\left(L_{1}\right)=v_{C} ; & v_{2}\left(L_{2}\right)=v_{B} \\
v_{1}^{\prime}\left(L_{1}\right)=\varphi_{C} ; & v_{2}^{\prime}\left(L_{2}\right)=\varphi_{B}
\end{array}
$$

with $\alpha=J J^{\prime} /(A \cos \varphi)$ rotation angle at the cantilever support corresponding to the deformation of the masonry triangle PJK in Fig. 3 (a) and considered as rigid, since the real variation of this angle do not determine sensible changes in the resultant stress maps. 

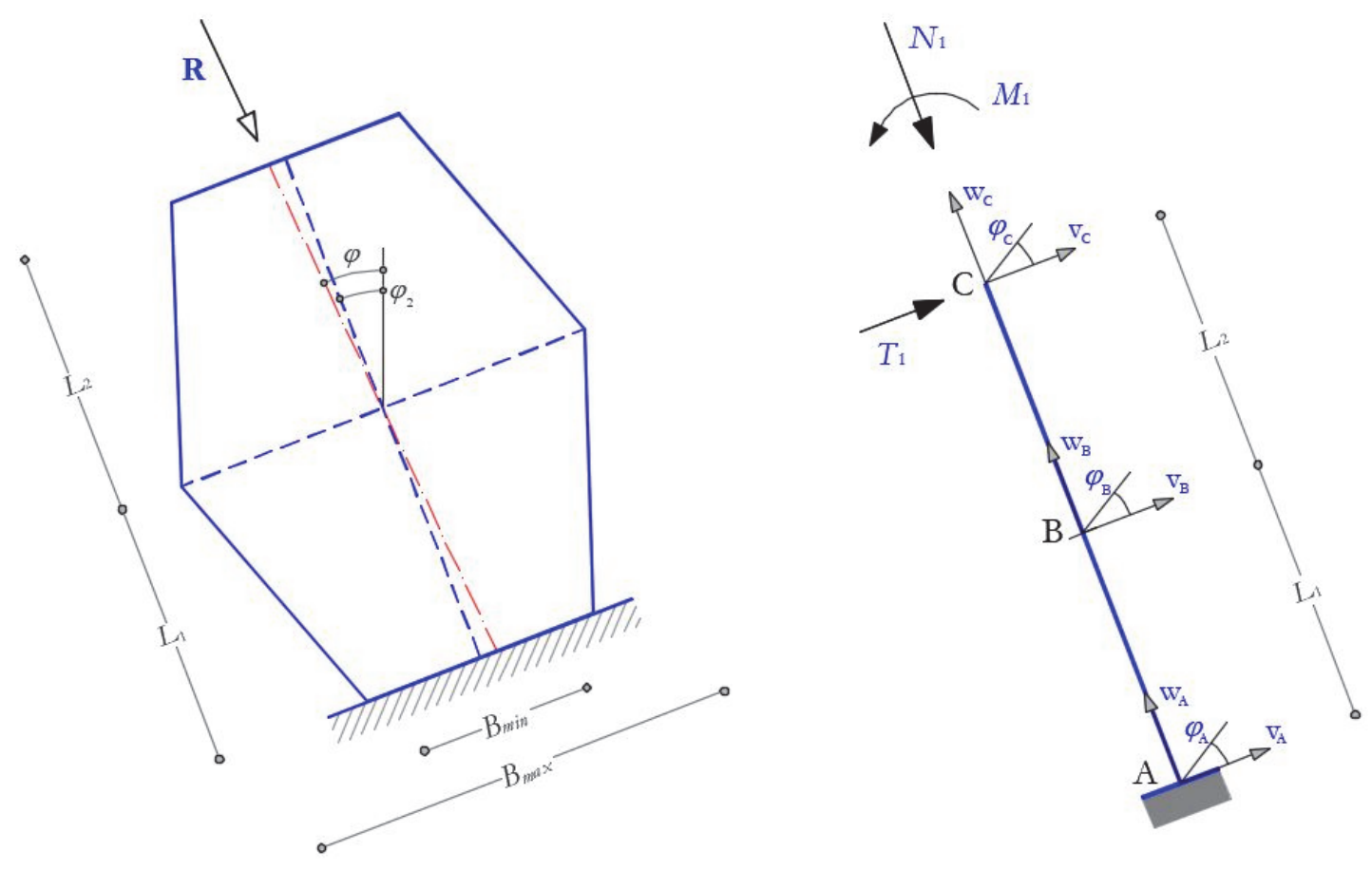

Figure 4: (a) Masonry strut within the panel; (b) Corresponding cantilever beam.

\section{NUMERICAL RESULTS COMPARISON}

7 he numerical tests have been performed considering a masonry wall with dimensions $900 \times 1500 \times 120 \mathrm{~mm}^{3}$, loaded with a constant vertical distributed load of $50 \mathrm{kN}$ and a Young modulus of $130 \mathrm{Mpa}$. The shear load T increases till the final value of $27 \mathrm{kN}$ (Tab. 1).

\begin{tabular}{ccccccc}
\hline & $\mathrm{a}$ & $\mathrm{b}$ & $\mathrm{c}$ & $\mathrm{d}$ & $\mathrm{e}$ & $\mathrm{f}$ \\
$\mathrm{N}[\mathrm{kN}]$ & 50 & 50 & 50 & 50 & 50 & 50 \\
$\mathrm{~T}[\mathrm{kN}]$ & 0 & 10 & 15 & 20 & 25 & 27 \\
\hline
\end{tabular}

Table 1: Valu

es of the vertical and horizontal loads on the masonry panel

Fig. 5 reports the stress maps obtained with the 1-D minimum potential energy approach [28].

The case d) of Fig. 5 has been examined with 2-D minimum complementary energy approach. The top and bottom relative displacements $U, V, \Phi$ have been derived from the absolute displacements obtained in the 1-D model analysis.

The $\Omega_{2}$ region is identified considering that the only compressive stresses run along the compression rays.

For the functions $g\left(\vartheta^{1}\right)$ and $g^{\prime}\left(\vartheta^{1}\right)$, as shown in Fig. $6(\mathrm{~b})$, a constant stress distribution along the rays are obtained and the corresponding values for the vertical and horizontal total loads are $\mathrm{T}=17.8 \mathrm{kN}$ and $\mathrm{N}=50.1 \mathrm{kN}$. The approximation of the corresponding values in Tab. 1 for the case $\mathrm{d}$ is considered sufficient. 
a

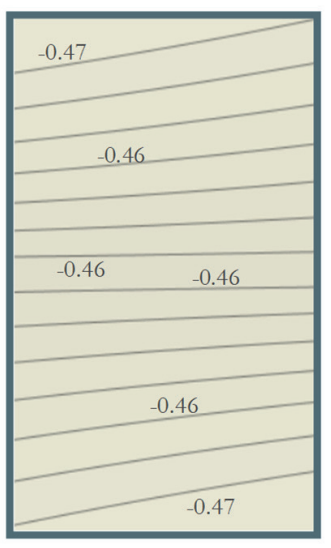

d

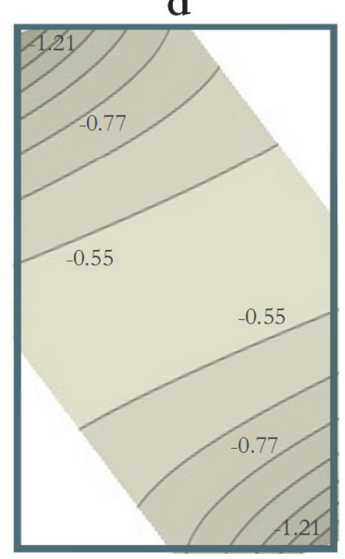

b

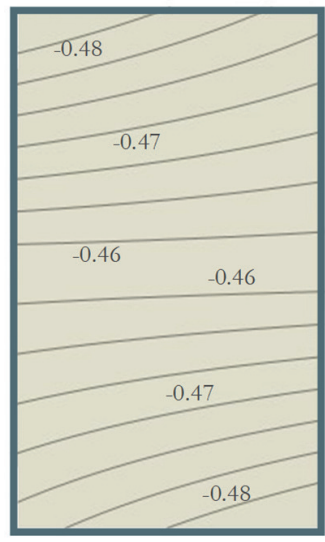

$\mathrm{e}$

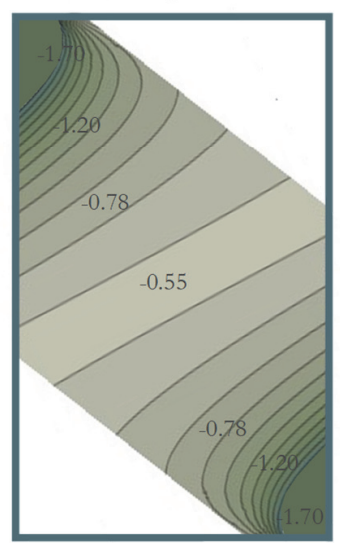

c

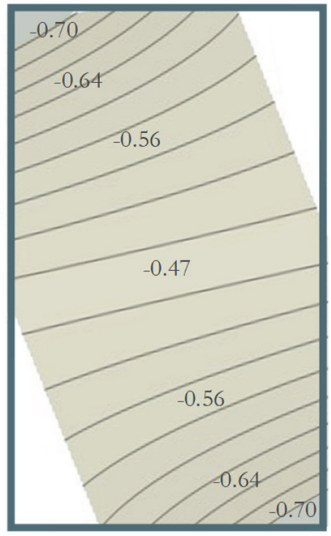

f

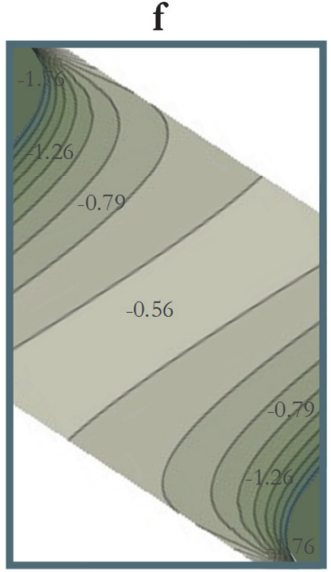

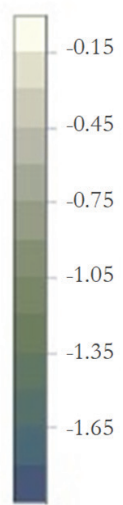

0.45

.75

.05

.35

65

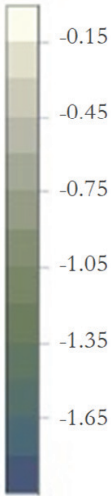

Figure 5: Stress contour plots for 1-D approach $\left[\mathrm{N} \mathrm{mm}^{-2}\right]$.

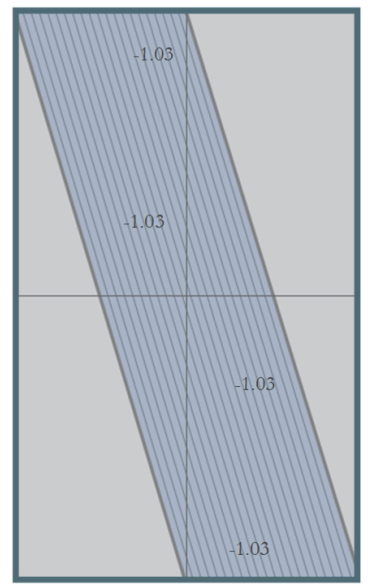

(a)

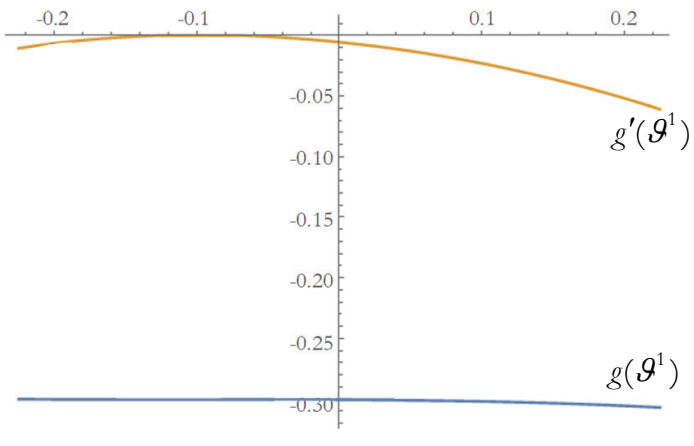

Figure 6: Stress map for 2-D approach (a) and representation of the functions $g\left(\vartheta^{1}\right)$ and $g^{\prime}\left(\vartheta^{1}\right)$ (b)

\section{CONCLUSIONS}

he essential elements of two variational approaches for the in plane behaviour of masonry walls, considered as NT structural elements, have been presented in this paper. Both the strategies allow the representation of the stress maps in the panel in case biaxial loading. The 1-D approach considers a diagonal strut embedded in the panel, 
whose geometry is imposed by the NT behavior and the solution corresponds to the minimum of total potential energy. The 2-D approach is conversely based on the minimum of the complementary energy, with a definition of the loaded area as a set of compressed rays and the loading actions on the panel are obtained as a solution of the procedure. The agreement between the results of the two procedures is satisfying, both with regard to the reactive area and to the stress intensity.

\section{REFERENCES}

[1] Guadagnuolo, M., Faella, G., Donadio, A., Ferri, L. (2014). Integrated evaluation of the Church of S. Nicola di Mira: Conservation versus safety. NDT \& E International, 68, pp. 53-65. DOI: 10.1016/j.ndteint.2014.08.002.

[2] Bergamasco, I., Gesualdo, A., Iannuzzo, A., Monaco, M. (2018). An integrated approach to the conservation of the roofing structures in the Pompeian domus, J. Cult. Herit., 31, pp. 141-151. DOI:10.1016/j.culher.2017.12.006.

[3] Betti, M., Galano, L., Petracchi, M. and Vignoli, A. (2015). Diagonal cracking shear strength of unreinforced masonry panels: a correction proposal of the b shape factor, B. Earthq. Eng., 13(10), pp. 3151-3186. DOI: $10.1007 / \mathrm{s} 10518-015-9756-8$

[4] Guadagnuolo M., Monaco, M. (2009). Out of plane behaviour of unreinforced masonry walls. In: Protection of Historical Buildings, 2, pp. 1177-1180, London, New York: CRC Press, Taylor \& Francis Group.

[5] Betti, M., Galano, L., Vignoli, A. (2008). Seismic response of masonry plane walls: A numerical study on spandrel strength, AIP Conf. Proc., 1020(1), pp. 787-794. DOI: 10.1063/1.2963915.

[6] Calderoni, B., Cordasco, E. A., Lenza, P., Pacella, G. (2011). A simplified theoretical model for the evaluation of structural behaviour of masonry spandrels, Int. J. Mater. Struct. Integrity, 5(2-3), pp. 192-214. DOI:10.1504/IJMSI.2011.041934

[7] Buonocore, G., Gesualdo, A., Monaco, M., Savino, M.T. (2014). Improvement of Seismic Performance of Unreinforced Masonry Buildings using Steel Frames. Civil-Comp Proceedings, 106. DOI:10.4203/ccp.106.117.

[8] Gatta, C., Addessi, D., Vestroni, F. (2018). Static and dynamic nonlinear response of masonry walls. International Journal of Solids and Structures, 155, pp. 291-303. DOI: 10.1016/j.ijsolstr.2018.07.028.

[9] Iannuzzo, A., Angelillo, M., De Chiara, E., De Guglielmo, F., De Serio, F., Ribera, F., Gesualdo, A. (2018). Modelling the cracks produced by settlements in masonry structures. Meccanica, 53(7), pp. 1857-1873. DOI: $10.1007 / \mathrm{s} 11012-017-0721-2$

[10]Iannuzzo, A., De Luca, A., Fortunato, A., Gesualdo, A., Angelillo, M. (2018b). Fractures detection in masonry constructions under horizontal seismic forces. Ing. Sismica, 35(3), pp. 87-103. DOI: 10.1007/s11012-017-0721-2

[11]Moseley, H. (1833). On a new principle in statics, called the principle of least pressure, London and Edinburgh Philosophical Magazine and Journal of Science, 3, 285-288.

[12]Euler, L. (1774). De pressione ponderis in planum cui incumbit, Novi Commentarii academiae scientiarum Petropolitanae 18, 289-329.

[13]Signorini, A.(1925). Un teorema di esistenza ed unicità nella statica dei materiali poco resistenti a trazione. Rend. Accad. Naz. Lincei, 401-406.

[14]Heyman, J. (1966). The stone skeleton, Int. J. Solids Struct., 2 (2), 265-279, DOI:10.1016/0020-7683(66)90018-7.

[15]Heyman, J. (1966). The stone skeleton. International Journal of Solids and Structures, 2(2), pp. 249-279. DOI: 10.1016/0020-7683(66)90018-7

[16]Heyman, J. (1977). Equilibrium of Shell Structures, Clarendon Press, Oxford, U.K.

[17]Heyman, J. (1995). The stone skeleton: structural engineering of masonry architecture, Cambridge University Press, Cambridge, U.K.

[18]Kooharian, A. (1953). Limit Analysis of Voussoirs and Concrete Arches, Journal of American Concrete Institute, 49(12), 317-328.

[19]Zienkiewicz O.C., Valliappan, S., King, I.P. (1968). Stress Analysis of Rock as a ‘No Tension’ Material, Géotechnique, 18(1), DOI: 10.1680/geot.1968.18.1.56.

[20]Chen, W.F. (1970). Extensibility of concrete and theorems of limit analysis. Journal of the Engineering Mechanics Division, 96(3), pp. 341-352.

[21]Heuzé, F.E., Goodman, R.E., Bornstein, A. (1971). Numerical analyses of deformability tests in jointed rock-“Joint Perturbation" and "No Tension" Finite Element solutions. Rock mechanics, 3(1), pp. 13-24.

DOI: $10.1007 / \mathrm{BF} 01243549$ 
[22]Giaquinta, M., Giusti, E. (1985). Researches on the equilibrium of masonry structures. Arch. Ration. Mech. Anal. 88(4), pp. 359-392, DOI: $10.1007 /$ BF00250872

[23]Del Piero, G. (1989). Constitutive equation and compatibility of the external loads for linear elastic masonry-like materials. Meccanica 24(3), pp. 150-162. DOI:10.1007/BF01559418

[24]Monaco, M., Bergamasco, I, Betti, M. (2018). A no-tension analysis for a brick masonry vault with lunette, Journal of Mechanics of Materials and Structures, 13(5), pp. 703-714, DOI: 10.2140/jomms.2018.13.703

[25]Crisfield, M.A., Packham, (1987). A mechanism program for computing the strength of masonry arch bridges, TRRL Research Report, 124.

[26]Fortunato, A. (2010). Elastic solutions for masonry-like panels. Journal of Elasticity, 98(1), pp. 87-110. DOI: $10.1007 /$ s10659-009-9219-z

[27]Gesualdo, A., Calderoni, B., Sandoli, A., Monaco, M. (2019). Minimum energy approach for the in-plane shear resistance of masonry panels. Ing. Sismica, 36(1), pp. 42-53.

[28]Monaco, M., Calderoni, B., Iannuzzo, A., Gesualdo, A. (2018). Behaviour of in-plane loaded masonry panels, Procedia Struct. Integrity, 11, pp. 388-393. DOI: 10.1016/j.prostr.2018.11.050

[29]Wolfram S. (2003) The Mathematica Book. Wolfram Media, Inc. Champaign, USA. 